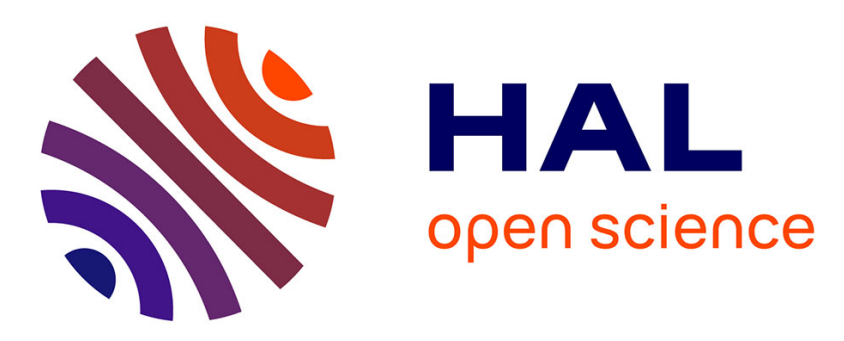

\title{
Model Predictive Direct Power Control for doubly fed induction generator based wind turbines with three-level neutral-point clamped inverter
}

\author{
Binh Quang Van Ngo, Pedro Rodriguez-Ayerbe, Sorin Olaru
}

\section{- To cite this version:}

Binh Quang Van Ngo, Pedro Rodriguez-Ayerbe, Sorin Olaru. Model Predictive Direct Power Control for doubly fed induction generator based wind turbines with three-level neutral-point clamped inverter. IECON 2016 - 42nd Annual Conference of the IEEE Industrial Electronics Society, Oct 2016, Florence, Italy. hal-01813380

\author{
HAL Id: hal-01813380 \\ https://hal.science/hal-01813380
}

Submitted on 11 Apr 2020

HAL is a multi-disciplinary open access archive for the deposit and dissemination of scientific research documents, whether they are published or not. The documents may come from teaching and research institutions in France or abroad, or from public or private research centers.
L'archive ouverte pluridisciplinaire HAL, est destinée au dépôt et à la diffusion de documents scientifiques de niveau recherche, publiés ou non, émanant des établissements d'enseignement et de recherche français ou étrangers, des laboratoires publics ou privés. 


\section{Model Predictive Direct Power Control for Doubly fed induction generator based wind turbines with Three-level Neutral-Point Clamped Inverter}

\author{
Binh Quang Van Ngo \\ CentraleSupélec, France
}

\author{
Pedro Rodriguez-Ayerbe \\ CentraleSupélec, France
}

\author{
Sorin Olaru \\ CentraleSupélec, France
}

Email: Binhvanquang.Ngo@supelec.fr Email: Pedro.Rodriguez@centralesupelec.fr Email: Sorin.Olaru@centralesupelec.fr

\begin{abstract}
The paper presents the control of a doubly fed induction generator (DFIG) connected with a three-level neutral point clamped (3L-NPC) inverter with. Model Predictive Direct Power Control (MPDPC) is synthesized using a dynamical model of the DFIG and 3L-NPC inverter. The principle of the proposed control scheme is to use the dynamical model to calculate predictions of the future values of the stator flux, rotor current and DC-link capacitor voltages for all possible configurations of voltage vectors. The active and reactive power can be estimated based on the stator flux and the rotor current. A cost function will be used to obtain the predicted profile which minimizes the error between the active, reactive powers and their references, balance the DC-link capacitor voltage and reduce the switching frequency and common-mode voltage. The optimal switching state that minimizes the cost function is selected and applied to the inverter. Simulation results under different conditions of wind speed are presented and compared with Deadbeat power control and Space Vector Modulation (DPC-SVM). The obtained results show the improved performances of the proposed control method.
\end{abstract}

\section{INTRODUCTION}

Nowadays, the global wind energy capacity has increased rapidly and became one of the fastest developing renewable technologies. Most of the major wind turbine manufactures are developing larger wind turbines in the 1.5-3 MW range. For such application, doubly fed induction generator represents an attractive solution thanks to its advantages: allows the power electronic converter to deal with approximately $30 \%$ of the generator power, reduce converter cost and power lost (Fig. 1) [1]. By using this configuration, it is possible to alow both bidirectional active and reactive power flow from the rotor side to grid through the rotor side converter (RSC) and grid side converter (GSC). Furthermore, from the technological point of view, the three-level neutral point-clamped inverter structure is considered a good solution for high power due to its advantages: reduction of the total harmonic distortion (THD) and increasing the capacity of the inverter thanks to a decreased voltage applied to each component.

Several methods have been proposed to control DFIG for wind energy generation. Most of the existing control method use the vector control based on the orientation of the flux stator (stator flux oriented) or stator voltage (stator voltage oriented). This method allows independently controlling the electromagnetic torque or active power and reactive power

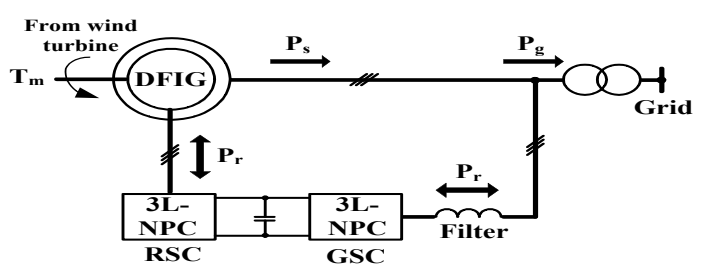

Fig. 1. Schematic diagram of DFIG based wind generation systems [1]

by means the components of the rotor current [1]. However, one drawback of this method is that its performance depend on accurate machine parameters such as stator and rotor resistance and mutual inductance. Another drawback of using PI controller is the tuning of gains in the whole operating range of wind speed. In addition, a complex modulation technique along with the DC-link capacitor voltages balancing is required to apply these techniques to $3 \mathrm{~L}-\mathrm{NPC}$ inverter.

Recently, direct torque control (DTC) [2] or direct power control (DPC) [3] have been proposed to improve the controller performance. The DTC controls the torque and rotor flux of the machine, while DPC controls the stator active and reactive powers. These methods used the hysteresis control and the inverter switching states, selected from a lookup table (LUT) based on the errors between the reference and estimated values, and rotor or stator flux position. Therefore, these methods do not require the current control loops and space vector modulation. Nevertheless, the drawback of LUT is that it has large active and reactive power ripple and switching frequency variation. In addition, a high sampling frequency is used for DTC/DPC to guarantee acceptable steady-state and dynamic performances. Several techniques have been developed to overcome this problem such as using DPC with space vector modulation (SVM) [4], deadbeat power control [5] and predictive control strategy [6]. Model predictive control is an alternative control technique that has been recently applied to DFIG thanks to its advantages, such as easy inclusion of nonlinearities in the model, delay compensation and no need of current control loop and modulation block [7], [8], [9].

The present paper proposes the model predictive direct power control (MPDPC) to control the active and reactive power for DFIG connected to a 3L-NPC inverter while main- 


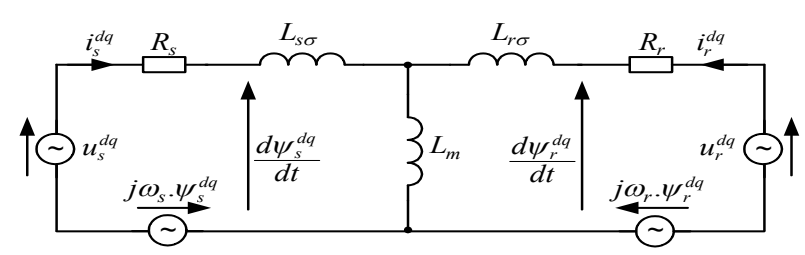

Fig. 2. Equivalent circuit of the DFIG in dq reference frame

taining the balance between the DC link capacitor voltage, reducing the switching frequency and the common-mode voltage. These objectives are accomplished through the cost function in a predictive control strategy. No current loop is considered and the inverter switches are directly obtained from cost function minimization. This control allows to improve the quality of the power regulation and to minimize the switching losses. A control horizon of two is used for the prediction, where only combination of inputs having a difference of one switch in the inverter is considered.

This paper is organized as follow: section 2 presents the mathematical model of direct power control for a DFIG connected to a 3L-NPC. Section 3 details the proposed control method. In section 4 , simulation results are represented and analyzed and finally section 5 draws the conclusion.

\section{MOdEL OF DFIG CONNECTED 3L-NPC INVERTER}

The doubly fed induction generator (DFIG) can be modelled by the equivalent circuit in dq coordinate (see [1]) based on stator fluxed orientation. The stator and rotor voltage vectors can be described based on the Fig. 2 as follows:

$$
\begin{aligned}
& u_{s}^{d q}=R_{s} i_{s}^{d q}+\frac{d \psi_{s}^{d q}}{d t}+j \omega_{s} \psi_{s}^{d q} \\
& u_{r}^{d q}=R_{r} i_{r}^{d q}+\frac{d \psi_{r}^{d q}}{d t}+j \omega_{r} \psi_{r}^{d q} .
\end{aligned}
$$

where $u_{s}^{d q}, i_{s}^{d q}, \psi_{s}^{d q}$ are the stator voltage, current and flux vector in dq reference frame while $u_{r}^{d q}, i_{r}^{d q}, \psi_{r}^{d q}$ are the rotor counterparts with respect to the stator.

$R_{s}, R_{r}$ are the stator resistance and the rotor resistance referred to the stator, $\omega_{s}, \omega_{m}$ are the synchronous speed of stator flux and angular rotor speed ( $\mathrm{rad} / \mathrm{s}), \omega_{r}=\omega_{s}-\omega_{m}=s \omega_{s}$ is the rotor angular frequency, with the coefficient $s$ denoting the slip.

The relationship between fluxes and currents are

$$
\begin{aligned}
& \psi_{s}^{d q}=L_{s} i_{s}^{d q}+L_{m} i_{r}^{d q} \\
& \psi_{r}^{d q}=L_{r} i_{r}^{d q}+L_{m} i_{s}^{d q}
\end{aligned}
$$

with $L_{s}$ and $L_{r}$ are the stator and rotor inductances and $L_{m}$ the magnetizing inductance.

By substituting the stator current $i_{s}^{d q}$ from equation (3) into equation (1), the stator flux dynamics can be expressed as follows:

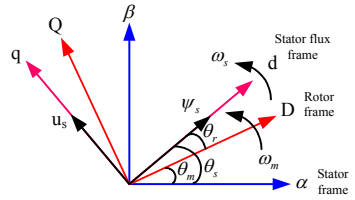

Fig. 3. Vector representation in different reference frame

$$
\frac{d \psi_{s}^{d q}}{d t}=\frac{1}{T_{s}}\left(-\left(1+j \omega_{s} T_{s}\right) \psi_{s}^{d q}+L_{m} i_{r}^{d q}+T_{s} u_{s}^{d q}\right) .
$$

where $T_{s}=\frac{L_{s}}{R_{s}}$ is the time constant of the stator.

By substituting equation (5) and the rotor flux $\psi_{r}^{d q}$ from equations (3) and (4) into equation (2), the dynamics of the rotor currents are represented as follows:

$$
\begin{aligned}
\frac{d i_{r}^{d q}}{d t} & =\frac{1}{\sigma L_{r}}\left(\psi_{s}^{d q}\left(\frac{L_{m}}{L_{s} T_{s}}+j \omega_{m} \frac{L_{m}}{L_{s}}\right)+u_{r}^{d q}\right) \\
& -\frac{1}{\sigma L_{r}}\left(i_{r}^{d q}\left(R_{\sigma}+j \omega_{r} \sigma L_{r}\right)+\frac{L_{m}}{L_{s}} u_{s}^{d q}\right) .
\end{aligned}
$$

where $R_{\sigma}=R_{r}+L_{m}^{2} / L_{s} T_{s}, \sigma=1-L_{m}^{2} / L_{s} L_{r}$ is the leakage coefficient.

Based on equations (5) and (6), the dynamical model of DFIG can be expressed in matrix form as below:

$$
\dot{x}=A x+B u
$$

where $x=\left[\begin{array}{c}\psi_{d s} \\ \psi_{q s} \\ i_{d r} \\ i_{q r}\end{array}\right], u=\left[\begin{array}{c}u_{d s} \\ u_{q s} \\ u_{d r} \\ u_{q r}\end{array}\right]$

$$
\begin{aligned}
A & =\left[\begin{array}{cccc}
-\frac{1}{T_{s}} & \omega_{s} & \frac{L_{m}}{T_{s}} & 0 \\
-\omega_{s} & -\frac{1}{T_{s}} & 0 & \frac{L_{m}}{T_{s}} \\
\frac{L_{m}}{L_{s} T_{s} \sigma L_{r}} & -\frac{\omega_{m} L_{m}}{L_{s} \sigma L_{r}} & -\frac{R_{\sigma}}{\sigma L_{r}} & \omega_{r} \\
\frac{\omega_{m} L_{m}}{\sigma L_{s} L_{r}} & \frac{L_{m}}{L_{s} T_{s} \sigma L_{r}} & -\omega_{r} & -\frac{R_{\sigma}}{\sigma L_{r}} \\
1 & 0 & 0 & 0 \\
0 & 1 & 0 & 0 \\
-\frac{L_{m}}{\sigma L_{s} L_{r}} & 0 & \frac{1}{\sigma L_{r}} & 0 \\
0 & -\frac{L_{m}}{\sigma L_{s} L_{r}} & 0 & \frac{1}{\sigma L_{r}}
\end{array}\right] .
\end{aligned}
$$

Because the stator is connected a grid, the stator flux is proportional to the grid in steady state. Neglecting the small drop in the stator resistance due to its relatively small value in comparison with the the stator reactance, we can obtain:

$$
u_{s} \approx \frac{d \psi_{s}}{d t} \approx \frac{d\left(\left|\psi_{s}\right| e^{j \omega_{s}}\right)}{d t} \approx j \omega_{s} \psi_{s}
$$




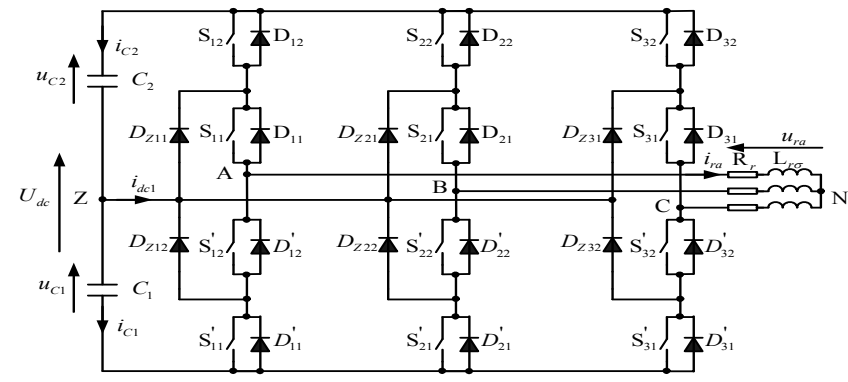

Fig. 4. The configuration of the rotor of DFIG connected 3L-NPC inverter

The system being oriented with stator flux (Fig. 3), based on equation (9) the component of stator flux can be expressed as follows [1]:

$$
u_{d s}=\psi_{q s}=0 ; u_{q s}=\hat{U}_{g} \approx \omega_{s} \psi_{s} \approx \omega_{s} \psi_{d s} .
$$

where $\hat{U}_{g}$ is the magnitude of the grid voltage.

The active and reactive powers in the stator can be expressed as follows:

$$
\begin{aligned}
& P_{s}=\frac{3}{2}\left(u_{d s} i_{d s}+u_{q s} i_{q s}\right)=-\frac{3}{2} \psi_{d s} \frac{L_{m}}{L_{s}} \omega_{s} i_{q r} \\
& Q_{s}=\frac{3}{2}\left(u_{q s} i_{d s}-u_{d s} i_{q s}\right)=\frac{3}{2} \hat{U}_{g}\left(\frac{\psi_{d s}}{L_{s}}-\frac{L_{m}}{L_{s}} i_{d r}\right) .
\end{aligned}
$$

Furthermore, by neglecting the coper power losses in the stator and rotor resistance, the active and reactive powers in stator and rotor can be expressed (see [1]) as follows:

$$
P_{r}=-s P_{s} ; Q_{r}=s Q_{s} .
$$

Based on the configuration shown in Fig. 4, the dynamic of neutral-point voltage is obtained using the rotor currents and the switching states of 3L-NPC inverter [10]:

$$
\frac{d u_{z}}{d t}=\frac{1}{6 C}\left(2\left|S_{a}\right|-\left|S_{b}\right|-\left|S_{c}\right|\right) i_{D r}+\frac{\sqrt{3}}{6 C}\left(\left|S_{b}\right|-\left|S_{c}\right|\right) i_{Q r} .
$$

where $S_{x}$ represents the state of a leg and has three possible values: $[-1,0,1]$. In addition, the rotor voltage which will be injected into DFIG, is also the inverter output voltage of $3 \mathrm{~L}$ NPC. The inverter output voltage in rotor reference frame $u_{i n v}^{D Q}$ can be estimated by measuring DC link voltage and exploiting the knowledge of the current switching state. After the Clarke transformation, this can be expressed as [10]:

$$
u_{i n v}^{D Q}=\frac{U_{d c}}{3}\left(S_{a}-\frac{S_{b}}{2}-\frac{S_{c}}{2}+j \frac{\sqrt{3}}{2}\left(S_{b}-S_{c}\right)\right) .
$$

Consequently, the rotor voltage referred to the stator in dq reference frame $\left(u_{r}^{d q}\right)$ can be calculated using rotational transformation and $K$ being the ratio of the stator voltage to the rotor voltage of the DFIG as [1]:

$$
u_{r}^{d q}=K u_{i n v}^{D Q} e^{-j \theta_{r}} .
$$

The rotor current referred to the stator in dq reference frame $\left(i_{r}^{d q}\right)$ can be calculated from the rotor current in rotor reference $\left(i_{r}^{D Q}\right)$ by using rotational transformation here:

$$
i_{r}^{d q}=\frac{1}{K} i_{r}^{D Q} e^{-j \theta_{r}} .
$$

In an inverter driven system, the common-mode voltage (CMV) $u_{c m}$ is defined as the voltage between the stator neutral $(\mathrm{N})$ and the neutral-point voltage $(\mathrm{Z})$, it can be expressed as [7]:

$$
u_{c m}=\frac{u_{A Z}+u_{B Z}+u_{C Z}}{3}
$$

with the inverter output voltage $u_{A Z}, u_{B Z}$ and $u_{C Z}$ of $3 \mathrm{~L}$ NPC inverter are calculated (see [10]) as a function of the DC link voltage and switching states:

$$
u_{A Z}=S_{a} \frac{U_{d c}}{2} ; u_{B Z}=S_{b} \frac{U_{d c}}{2} ; u_{C Z}=S_{c} \frac{U_{d c}}{2} .
$$

\section{MODEL PREDICTIVE DIRECT POWER CONTROL APPLIED TO DFIG CONNECTED 3L-NPC}

The aim of the predictive direct power control scheme is to minimize the error between the predicted active and reactive power and their reference values, to maintain voltage balance of the capacitor and to reduce the switching frequency and common-mode voltage. In order to achieve these objectives, the cost function for the DFIG connected 3L-NPC inverter with two-step prediction can be expressed as follows [7]:

$$
\begin{aligned}
g & =\left|P_{s}^{*}(k+2)-P_{s}^{p}(k+2)\right|+\left|Q_{s}^{*}(k+2)-Q_{s}^{p}(k+2)\right| \\
& +\lambda_{d c}\left|u_{z}^{p}(k+2)\right|+\lambda_{n} n_{c}+\lambda_{c m}\left|u_{c m}\right|
\end{aligned}
$$

where $\lambda_{d c}, \lambda_{n}$ and $\lambda_{c m}$ are the weighting factors of the capacitor voltage balancing, the reduction of commutation and CMV. $n_{c}$ penalizes the number of switching changes when the switching state $S(k)$ is applied compared with previous state $S(k-1)$. It can be expressed as:

$$
\begin{aligned}
n_{c} & =\left|S_{a}(k)-S_{a}(k-1)\right|+\left|S_{b}(k)-S_{b}(k-1)\right| \\
& +\left|S_{c}(k)-S_{c}(k-1)\right| .
\end{aligned}
$$

In the real time implementation of the system, because of calculation time of the control law, there will be a sample time delay in the actuation [7], [8]. A simple solution to compensate the computational delay is to compute at time instant $k$ the cost function corresponding to time instant $k+1$ using an estimation of the state at time $k+1$ and then the optimal switching state is applied at time $k+1$. As previously mentioned, there are 27 voltage vectors which have to be evaluated within one step prediction. When two steps are considered for prediction, 


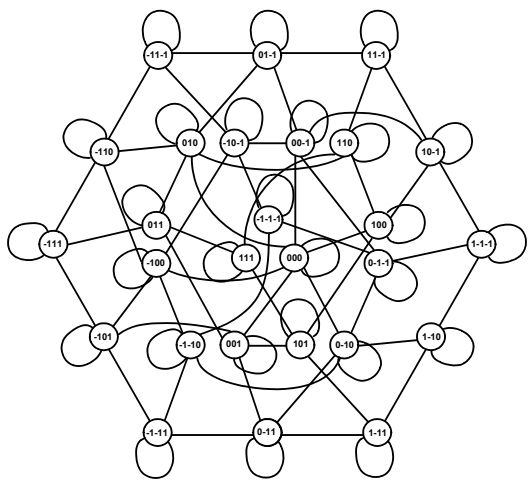

Fig. 5. The switching transitions of 3L-NPC inverter

a discrete set of $27^{2}$ possible trajectories of the vector voltage have to be considered. Consequently, their evaluation leads to large number of cost computations and make difficult to implement the algorithm in practice. To reduce the number of real time evaluations only combinations of inputs having one switching variation are considered, as illustrated in Fig. 5. For

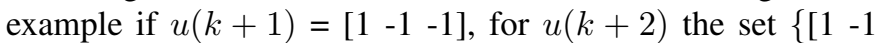

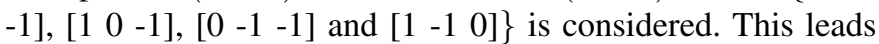
to 135 combinations. Therefore, the computations required are limited with respect to the total of $27^{2}=729$ trajectories.

The equation (7) can be discretized considering $T_{s p}$ as a sampling period and $k$ as the sampling time by using zeroorder hold $(\mathrm{ZOH})$ with no delay:

$$
x(k+1)=A_{d} x(k)+B_{d} u(k)
$$

where

$$
A_{d}=e^{A T_{s p}}, B_{d}=\int_{0}^{T_{s p}} e^{A\left(T_{s p}-d \tau\right)} B d \tau \simeq B T_{s p} .
$$

Since the active and reactive powers references are DC quantities, to reduce the computational time and the oscillations in the reference powers when a sudden change occurs, the extrapolation can be simplified as follows:

$$
P_{s}^{*}(k+2)=P_{s}^{*}(k) ; Q_{s}^{*}(k+2)=Q_{s}^{*}(k) .
$$

Finally, the objective of proposed predictive control can be obtained by evaluation of cost function for all trajectories (see algorithm 1).

\section{Simulation Results}

With the aim to validate the effectiveness of the model predictive direct power control (MPDPC) strategy for DFIG under different modes of speed operation, the whole control scheme has been simulated using Matlab software with the parameters as indicated in Table I.

In order to verify the dynamic performance, we perform a comparison between MPDPC and deadbeat power control with space vector modulation (DPC-SVM) [5] for different conditions of references and the same parameters in Table I. To generate the same average switching frequency per $\overline{\text { Algorithm } 1 \text { Algorithm of model predictive direct power }}$ control for DFIG connected 3L-NPC inverter

Measure $i_{s}(k), i_{r}(k), u_{z}(k), u_{s}(k), \omega_{m}$ and $U_{d c}$; Read the reference values $P_{s}^{*}(k)$ and $Q_{s}^{*}(k)$

Estimation of stator flux $\psi_{d s}(k)$; Extrapolation of references $P_{s}^{*}(k+2), Q_{s}^{*}(k+2)$ and $u_{s}^{d q}(k+1)$

\%comment: $x_{\text {opt }}, g_{\text {opt }}$ are the optimal values of the switching states and cost function $\%$

Initialize optimal values: $x_{o p t}, g_{o p t}$

Predict stator flux: $\psi_{d s}^{p}(k+1)$

for $i=1$ to 27 do

Compute predictions: $i_{d r}^{p}(k+1), i_{q r}^{p}(k+1)$ and $u_{z}^{p}(k+1)$

Estimate the values: $n_{c}$ and $u_{c m}$

Predict corresponding switching transitions

for $j=1$ to $m$ do \%comment: $\mathrm{m}=$ length(corresponding switching transitions)

2)

Predict: $i_{d r}^{p}(k+2), i_{q r}^{p}(k+2), \psi_{d s}^{p}(k+2)$ and $u_{z}^{p}(k+$

Estimation of power: $P_{s}^{p}(k+2)$ and $Q_{s}^{p}(k+2)$

Compute the cost function $\mathrm{g}$

$$
\begin{aligned}
& \text { if } g<g_{o p t} \text { then } \\
& \quad g_{o p t}=g ; x_{o p t}=i \\
& \text { end if }
\end{aligned}
$$

end for

\section{end for}

Store the present value of $x_{o p t}$, apply $S_{a}, S_{b}, S_{c}$

semiconductor $\overline{f_{s w}}=1.5 \mathrm{kHz}$, the sampling frequency $f_{\text {svm }}$ $=3 \mathrm{kHz}$ is considered for the DPC-SVM and the sampling frequency of the MPDPC $f_{s}$ is $20 \mathrm{kHz}$.

With the purpose of evaluate the steady state performance, the mean absolute percentage error (MAPE) is used which can be expressed:

$$
M A P E=\frac{1}{n} \sum_{i=1}^{n}\left|\frac{y_{i}^{*}-y_{i}}{y_{i}^{*}}\right|
$$

TABLE I

SIMULATION PARAMETERS

\begin{tabular}{|c|c|l|}
\hline Parameter & Value & Description \\
\hline$P_{\text {rated }}$ & $2[\mathrm{MW}]$ & Rated stator three phase active power \\
$U_{s-\text { rated }}$ & $690[\mathrm{~V}]$ & Line to line nominal stator voltage \\
$U_{r-\text { rated }}$ & $2070[\mathrm{~V}]$ & Line to line nominal rotor voltage \\
$I_{s-\text { rated }}$ & $1760[\mathrm{~A}]$ & Each phase nominal stator current \\
$n_{s-\text { rated }}$ & $1500[\mathrm{rpm}]$ & Synchronous speed \\
$\mathrm{p}$ & 2 & The number pairs of poles \\
$R_{s}$ & $2.6[\mathrm{~m} \Omega]$ & Stator resistance \\
$R_{r}$ & $2.9[\mathrm{~m} \Omega]$ & Rotor resistance \\
$L_{\sigma s}$ & $87[\mu \mathrm{H}]$ & Stator leakage inductance \\
$L_{\sigma r}$ & $87[\mu \mathrm{H}]$ & Rotor leakage inductance \\
$L_{m}$ & $2.5[\mathrm{mH}]$ & Mutual inductance \\
$\mathrm{J}$ & $0.314\left[\mathrm{~kg} . \mathrm{m}^{2}\right]$ & Moment of inertia \\
$f_{s}$ & $50[\mathrm{~Hz}]$ & Frequency of the grid \\
$f_{s p}$ & $20[\mathrm{kHz}]$ & Sampling frequency of MPDPC \\
$f_{s v m}$ & $3[\mathrm{kHz}]$ & Sampling frequency of DPC-SVM \\
$U_{d c}$ & $1200[\mathrm{~V}]$ & DC link voltage \\
$C_{d c}$ & $16000[\mu \mathrm{F}]$ & DC link capacitor \\
\hline
\end{tabular}


where $y_{i}^{*}$ is the reference vector and $y_{i}$ is the measurement vector.

On the other hand, in order to estimate the average switching frequency per semiconductor $\left(\overline{f_{s w}}\right)$ of MPDPC, the following expression proposed in [7] is used:

$$
\overline{f_{s w}}=\sum_{x=a, b, c} \frac{f_{s w_{1 x}}+f_{s w_{2 x}}}{6}
$$

where $f_{s w_{1 x}}, f_{s w_{2 x}}$ are the switching frequency of each upper switch.

With the purpose of control the power factor (PF), the reactive power reference is given by:

$$
Q_{s_{-} r e f}=P_{s_{-} r e f} \frac{\sqrt{1-P F^{2}}}{P F}
$$

The DFIG was assumed to be in speed control, i.e., the rotor speed is set externally, and has slow changes because of the large inertia of the wind turbine. In order to observe the dynamics response of the DFIG, various active and reactive power steps with synchronous speed (1500 rpm) were carried out. The initial active power and power factor reference were $2 \mathrm{MW}$ and $\mathrm{PF}=1$ at $0.5 \mathrm{~s}$. The active power reference presents a steps from $-2 \mathrm{MW}$ to $-1 \mathrm{MW}$ at $1 \mathrm{~s}$, then steps from -1 MW to $-1.5 \mathrm{MW}$ at $2 \mathrm{~s}$ (Fig. 6(a)). While the PF is changed from 1 to 0.9 at $1 \mathrm{~s}$, then is changed from 0.9 to -0.9 at $1.5 \mathrm{~s}$ and from -0.9 to 0.9 at $2 \mathrm{~s}$. The reactive power reference is changed using equation (26) from 0 Var to -0.484 MVar at 1 $\mathrm{s}$, then is changed from -0.484 MVar to 0.484 MVar at $1.5 \mathrm{~s}$ and from 0.484 MVar to -0.727 MVar at $2 \mathrm{~s}$ (Fig. 6(c)).

As the machine operates at synchronous speed, slip is zero. Consequently, the power of the rotor is approximately zero (Figs. 6(b). Figs. 6(b) and 6(d) indicate that the active power is tracking their references with fast dynamics and without affecting the reactive power (the average computation time of the algorithm is $0.2 \mathrm{~ms}$ in a $3.7 \mathrm{GHz}$, i7 CPU, permitting a real time implementation). The proposed method presents better performance compared to the DPC-SVM. The mean absolute percentage error of active and reactive power for DPC-SVM is $8.74 \%$ and $13.1 \%$, whereas, for the proposed method they are $1.32 \%$, and $1.98 \%$, respectively. The transient responses of the stator current and its FFT are illustrated in Fig. 7, where the THD is found to be lower for the proposed method in contrast to the DPC-SVM.

One of the important issues of 3L-NPC structure is balancing voltage of the DC link capacitor. The Fig. 8 shows that the voltage of DC link capacitor remains balanced with MAPE of DC link capacitor voltages deviation $0.21 \%$ in spite of the transition of power references.

The performance of the proposed method is also examined during varying the rotor speed from 1200 to $1800 \mathrm{rpm}$ as shown in Fig. 9. The active power reference is changed from $-2 \mathrm{MW}$ to $-1 \mathrm{MW}$ at $1.5 \mathrm{~s}$ and from $-1 \mathrm{MW}$ to $-1.5 \mathrm{MW}$ at $2 \mathrm{~s}$ (Fig. 11). While the reactive power reference is changed from -1.24 MVar to 0.62 MVar at $1.5 \mathrm{~s}$ and from 0.62 MVar to 0 Var at $2 \mathrm{~s}$. When the rotor speed of the generator is

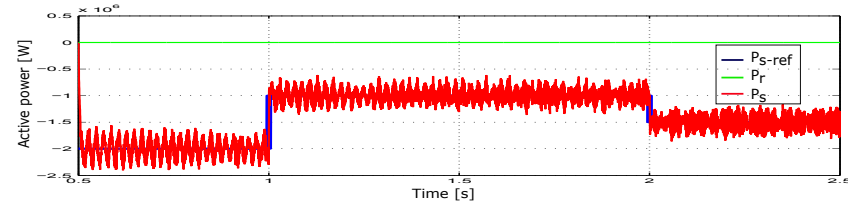

(a) Generated active power for DPC-SVM

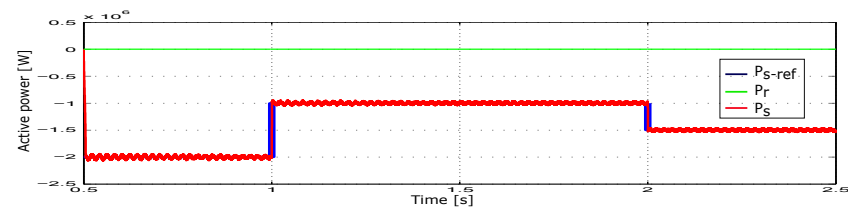

(b) Generated active power for MPDPC

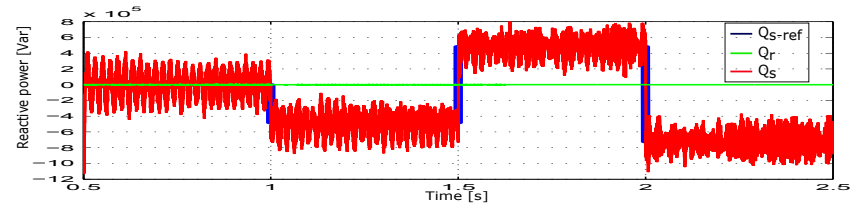

(c) Generated reactive power for DPC-SVM

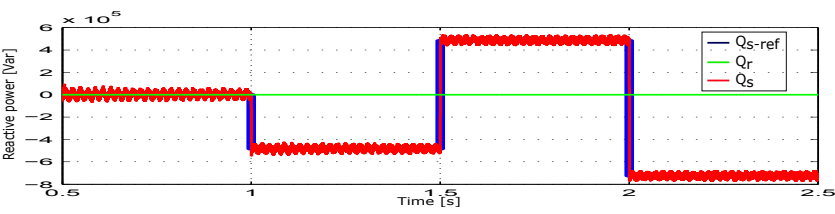

(d) Generated reactive power for MPDPC

Fig. 6. The dynamic response of active and reactive power with synchronous speed for DPC-SVM and MPDPC

greater than synchronous speed, the slip is negative. Thus, the rotor power $P_{r}$ will be transferred from the generator rotor to the grid through the rotor converters of the DFIG, whereas the RSC operates as a rectifier and the GSC as an inverter. Therefore, the powers delivered to the grid $P_{g}$ and $Q_{g}$ which are the sum of the stator and rotor powers can be illustrated in Figs. 11(a) and 11(b).

Finally, Fig. 10 shows the common mode voltage is reduced by changing the weighting factor value $\lambda_{c m}$ while maintaining an acceptable quality of current $(\mathrm{THD}=2.74 \%)$ and power with MAPE of active and reactive powers is $1.3 \%$ and $1.89 \%$ (Fig. 11). A high CMV can cause overvoltage stress in the winding insulation of the electrical machine fed by power converter, producing deterioration and reducing the lifetime of the machine.

\section{CONCLUSIONS}

A new direct power control method for DFIG system has been proposed to control the active and reactive powers directly in this study. First, the mathematical model of DFIG conneted 3L-NPC inverter is established, and then the cost function, which contains the power errors, the capacitor voltage balancing and the reduction of the switching frequency, is constituted. In order to verify the performance of control scheme, there is a comparison between DPC-SVM and proposed method. The simulation results show that this method can successfully track the active and reactive powers, main- 


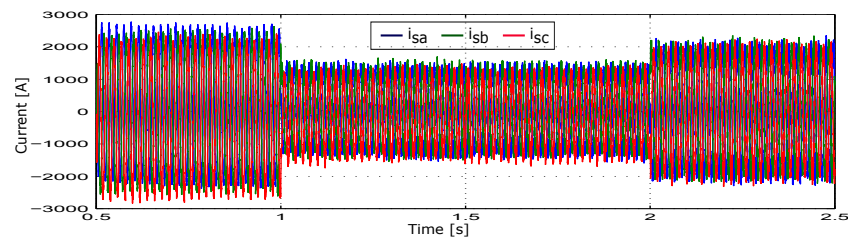

(a) The transient response of the stator current for DPC

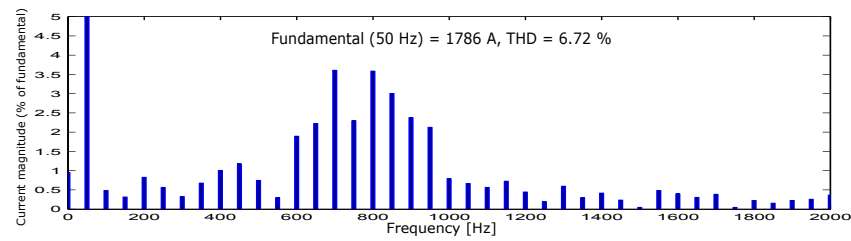

(b) Fast Fourier Transform of the stator current for DPC

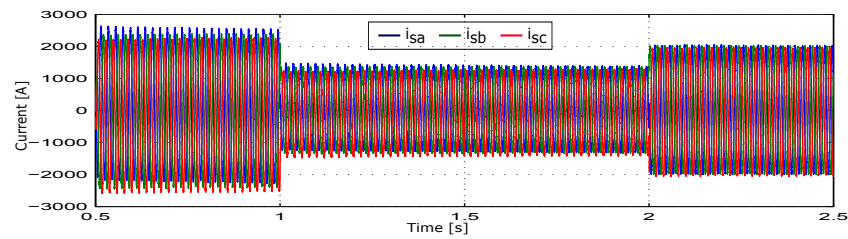

(c) The transient response of the stator current of MPDPC

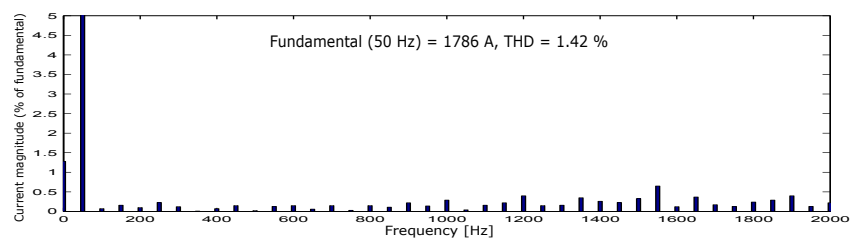

(d) Fast Fourier Transform of the stator current for MPDPC

Fig. 7. The dynamic response and FFT of the stator current with synchronous speed for DPC-SVM and MPDPC

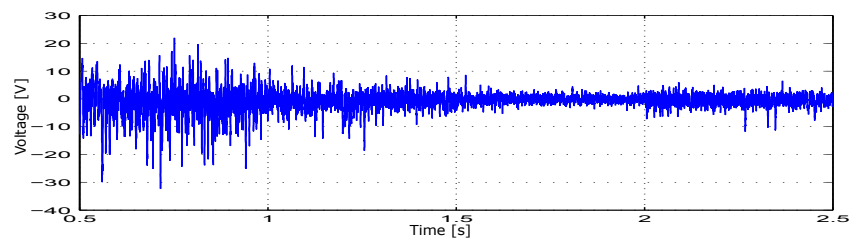

Fig. 8. Performance of the neutral-point voltage $u_{z}$

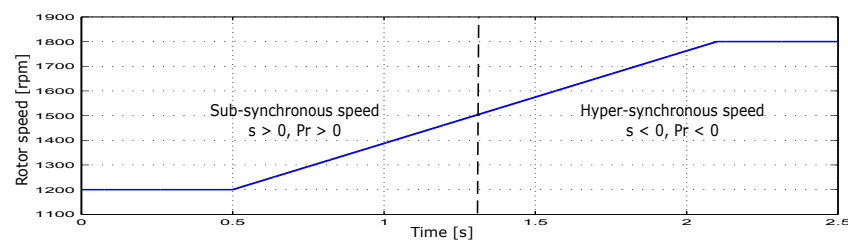

Fig. 9. Rotor angular speed time response

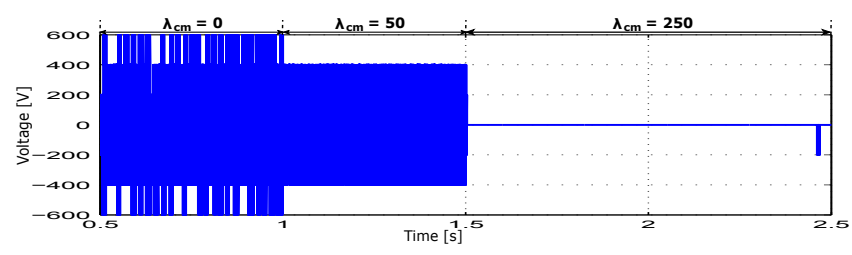

Fig. 10. Performance of common-mode voltage

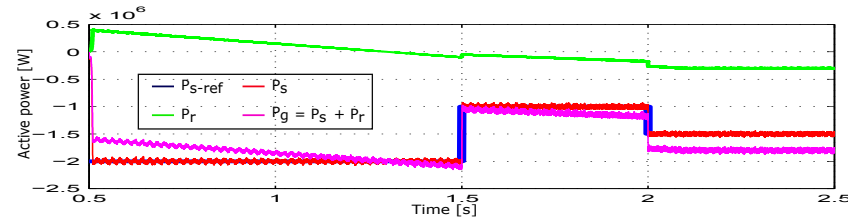

(a) Generated active power

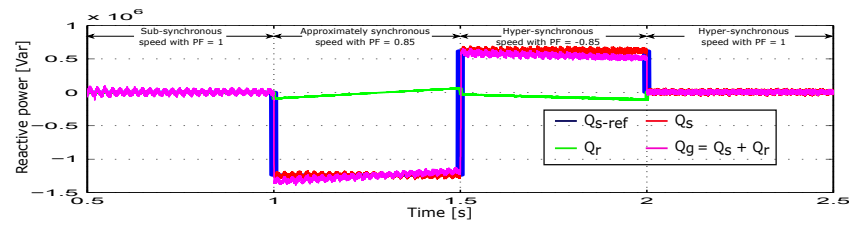

(b) Generated reactive power

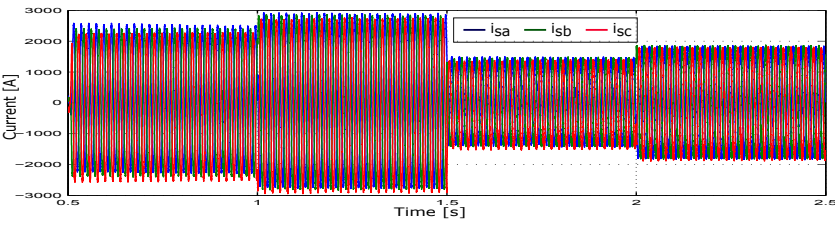

(c) Stator current

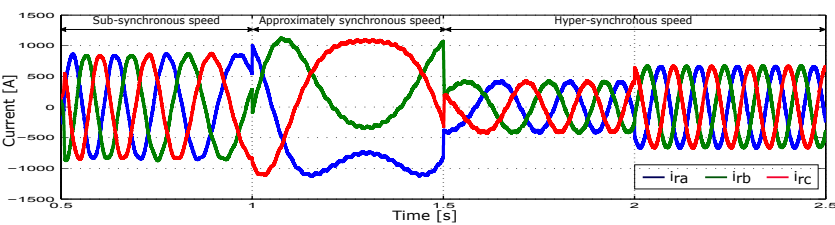

(d) Rotor current

Fig. 11. The dynamic response of the power and current with rotor speed variation

tain their balanced capacitor voltages, reduce the switching frequency and common-mode voltage. Furthermore, by using proposed method we can reduce the switching losses and high number of calculations while maintaining an acceptable quality of current and power. The linear PI controllers for the power, current loops and the modulation block are further eliminated. Therefore, the proposed method is an interesting alternative to control the DFIG connected 3L-NPC inverter.

\section{REFERENCES}

[1] G. Abad, J. Lopez, M. A. Rodriguez, L. Marroyo, and G. Iwanski, Doubly fed induction machine-Modelling and control for wind energy generation. John Wiley and Sons, 2011.

[2] J. Hu and X. Yuan, "Vsc-based direct torque and reactive power control of doubly fed induction generator," Journal Renewable Energy, vol. 40, pp. 13-23, 2012.

[3] L. Xu and P. Cartwright, "Direct active and reactive power control of dfig for wind energy generation," IEEE Transactions on Energy Conversion, vol. 21, no. 3, pp. 750-758, 2006.

[4] M. V. Kazemi, A. S. Yazdankhah, and H. M. Kojabadi, "Direct power control of dfig based on discrete space vector modulation," Journal Renewable Energy, vol. 35, pp. 1033-1042, 2010.

[5] A. J. S. Filho and E. Ruppert, "A deadbeat active and reactive power control for doubly fed induction generator," Electric Power Components and Systems, vol. 38, no. 5, pp. 592-602, 2010.

[6] J. Sayritupac, E. Albanez, J. Rengifo, J. M. Aller, and J. Restrepo, "Predictive control strategy for dfig wind turbines with maximum power point tracking using multilevel converters," in Proceeding of workshop on Power Electronics and Power Quality Applications (PEPQA), Bogota, 2015, pp. 1-6. 
[7] J. Rodriguez and P. Cortes, Predictive Control of Power Converters and Electrical Drives. John Wiley, 2012.

[8] R. Errouissi, A. Al-Durra, S. M. Muyeen, S. Leng, and F. Blaabjerg, "Offset-free direct power control of dfig under continuous-time model predictive control," IEEE Transaction On Power Electronics, 2016.

[9] D. Sun and X. Wang, "Low-complexity model predictive direct power control for dfig under both balanced and unbalanced grid conditions," IEEE Transactions on Industrial Electronics, 2016, (to appear).

[10] B. Q. V. Ngo, P. R. Ayerbe, and S. Olaru, "Model predictive control with two-step horizon for three-level neutral-point clamped inverter," in Proceeding of 20th International Conference on Process Control, Slovak, 2015, pp. 215-220. 